\title{
Applying evidence-based device care in cardiovascular patients: which patient with heart failure and what device?
}

\author{
${ }^{1} \mathrm{JG}$ Cleland, ${ }^{2} \mathrm{~L}$ Buga, ${ }^{3} \mathrm{~J}$ Ghosh, ${ }^{4} \mathrm{M}$ Nasir \\ ${ }^{1}$ Professor of Cardiology; ${ }^{2}$ Research Fellow in Cardiology; ${ }^{3}$ Specialist Registrar in Cardiology; ${ }^{4}$ Consultant Cardiologist, \\ Division of Cardiovascular-Respiratory and Metabolic Medicine, Hull E York Medical School, Kingston upon Hull, UK
}

\begin{abstract}
In terms of engineering, clinical understanding and application, device therapy remains in its infancy. In clinical trials, implantable cardiac defibrillators (ICDs) have greatly reduced the rate of sudden death and had a modest impact on mortality in a relatively broad range of patients. They do not generally improve symptoms and may make them worse. Cardiac resynchronisation therapy (CRT) devices have been used more selectively - probably far too selectively - and have shown substantial improvement in symptoms and a large reduction in mortality both by reducing sudden death and death due to heart failure. These effects are not explained solely by improved ventricular function, and the clinical response to therapy has so far not been predicted well by any method of assessing cardiac function or dyssynchrony. Reduction in brady-arrhythmia-triggered sudden death may be an underestimated benefit of biventricular pacing. In recent trials, heart failure patients implanted with a device have had a remarkably low mortality. This forces the clinical community to contemplate universal device use for patients with heart failure, except in those who have irremediable, life-limiting, non-cardiac disease. For most patients this should be CRT or a combination of CRT and an ICD (CRT-D).
\end{abstract}

KEYWORDS Cardiac resynchronisation therapy, heart failure, implantable cardiac defibrillators, morbidity, mortality, symptoms

DECLARATION OF INTERESTS Prof. Cleland has received research funding from Medtronic and Biotronik and speaker fees from both of the above as well as St Jude Medical and Boston Scientific.

\section{INTRODUCTION}

Sudden death, stroke and heart failure are the three big cardiovascular killers. Myocardial infarction (MI) that does not result in sudden death or heart failure is rarely fatal. ${ }^{1,2}$ Sudden death is probably the expression of both arrhythmic and vascular events, ${ }^{3}$ and its prevention is likely to require a strategy that manages both arrhythmic and vascular risk. There is reasonably good evidence that effective pharmacological treatment of post-infarction left ventricular (LV) dysfunction reduces the risk of sudden death and overall mortality. ${ }^{3,4}$ The evidence that treatment directed at the coronary arteries, including percutaneous or surgical revascularisation, reduces the risk of sudden death or prolongs life outside of the setting of an acute coronary syndrome is dubious. 5 .,6 Many stroke patients recover without major disability, and good treatment of hypertension and lipids will reduce the risk of recurrence, ${ }^{7-9}$ although the evidence for antiplatelet therapy is in doubt. ${ }^{10}$ This leaves heart failure as the most recalcitrant and increasingly common serious cardiovascular problem.

The prognosis of patients in clinical trials of heart failure remains generally poor. ${ }^{11,12}$ Patients with mild to moderate symptoms and objective confirmation of cardiac
Correspondence to JG Cleland, Department of Cardiology, Castle Hill Hospital, University of Hull, Hull \& York Medical School, Kingston upon Hull HU6 5JQ, UK

tel. +44 (0) I482 46 I776 e-mail j.g.cleland@hull.ac.uk dysfunction still have an annual mortality of $10-15 \%$ per year." In clinical practice, mortality may be even higher and exceed $40 \%$ per year in patients who have survived a recent hospitalisation for worsening heart failure. ${ }^{13}$ Older patients fare less well. The average age of patients with heart failure in the UK is about 75 years, although somewhat lower for patients with heart failure and a low ejection fraction (EF). Heart failure is also characterised by troublesome symptoms that may be recurrently or persistently severe. For some patients prognosis and for other patients symptoms are the treatment priority.

Heart failure is not a single entity. Its aetiology and pathophysiology are complex. Most patients will have several reasons for developing symptoms and signs of heart failure. Heart failure may be due to valve disease; arrhythmias such as atrial fibrillation; cardiac pressure (e.g. hypertension) or volume (e.g. anaemia) overload; dilatation of the left ventricle with a reduced EF ('systolic' heart failure); or impaired compliance of the left ventricle with reduced filling ('diastolic' heart failure). Any cause of heart failure that cannot be corrected carries a similarly poor prognosis. ${ }^{14-16}$ However, each cause may require a different therapeutic approach, although some, such as the relief of congestion using diuretics, may be common to all. 
TABLE I Summary of NICE, SIGN, ESC and AHA/ACCF guidelines for implantable cardiac defibrillators

\begin{tabular}{|c|c|c|c|c|c|}
\hline & $\begin{array}{l}\frac{\overline{\tilde{u}}}{\mathbf{z}} \\
.\end{array}$ & $\frac{\tilde{n}}{\underline{U}}$ & 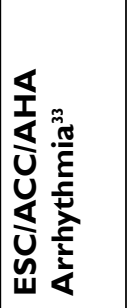 & 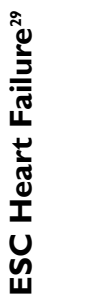 & 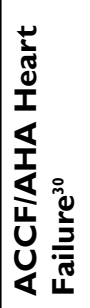 \\
\hline \multicolumn{6}{|l|}{ Primary } \\
\hline Aetiology & 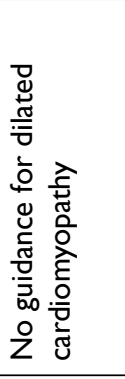 & 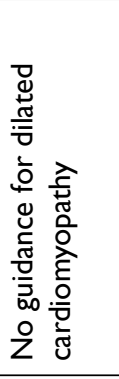 & 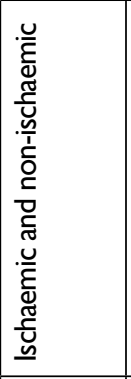 & 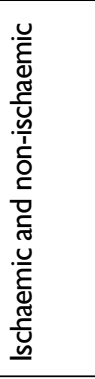 & 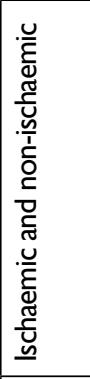 \\
\hline $\begin{array}{l}\text { Time } \\
\text { following MI }\end{array}$ & 4 weeks & 4 weeks & 40 days & $\begin{array}{l}40 \\
\text { days }\end{array}$ & $\begin{array}{l}40 \\
\text { days }\end{array}$ \\
\hline $\begin{array}{l}\text { Ejection } \\
\text { fraction }\end{array}$ & 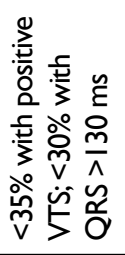 & $\stackrel{\circ}{\stackrel{\circ}{\sim}}$ & 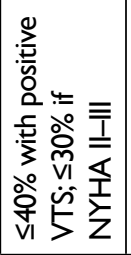 & $\stackrel{\circ}{\text { ஸे }}$ & ㅇํํ \\
\hline NYHA class & $<\mathrm{IV}$ & $<\mathrm{IV}$ & I-III & II-III & II-III \\
\hline $\begin{array}{l}\text { Familial } \\
\text { conditions }\end{array}$ & $\sqrt{ }$ & 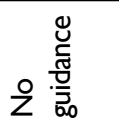 & $\sqrt{ }$ & 之 & 之 \\
\hline \multicolumn{6}{|l|}{ Secondary } \\
\hline $\begin{array}{l}\text { Survived } \\
\text { cardiac arrest }\end{array}$ & $\sqrt{ }$ & $\sqrt{ }$ & $\sqrt{ }$ & $\sqrt{ }$ & $\sqrt{ }$ \\
\hline $\begin{array}{l}\text { Symptomatic } \\
\text { VT }\end{array}$ & $\sqrt{ }$ & $\sqrt{ }$ & $\sqrt{ }$ & $\begin{array}{l}\text { EF } \\
\leq 40 \%\end{array}$ & $\sqrt{ }$ \\
\hline $\begin{array}{l}\text { Asymptomatic } \\
\text { VT }\end{array}$ & 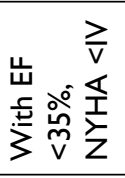 & 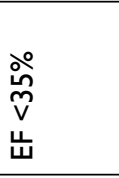 & Z & 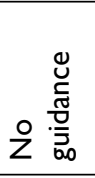 & 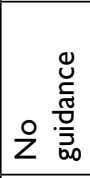 \\
\hline CRT-D & 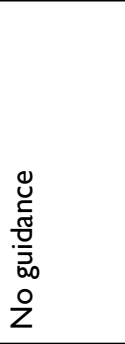 & 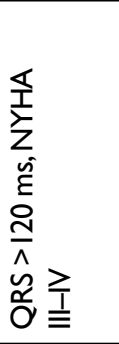 & 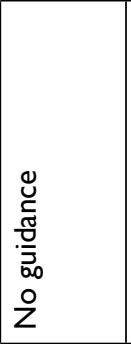 & 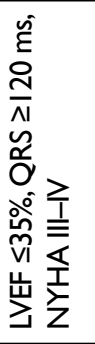 & 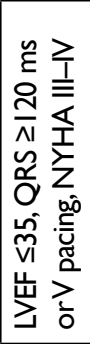 \\
\hline
\end{tabular}

Abbreviations: $\mathrm{ACCF}=$ American College of Cardiology Foundation; $\mathrm{AHA}$ $=$ American Heart Association; CRT-D = cardiac resynchronisation therapy defibrillator; $E F=$ ejection fraction; ESC = European Society of Cardiology; $\mathrm{LVEF}=$ left ventricular ejection fraction; NICE = National Institute for Health and Clinical Excellence; NYHA = New York Heart Association classification; SIGN = Scottish Intercollegiate Guidelines Network; VT = ventricular tachycardia; positiveVTS = spontaneous non-sustained VT on Holter monitoring and inducibleVT during electrophysiology study
The 20th century saw the development of devices for treating arrhythmias. The 2 Ist century has started with an explosion of interest and evidence that devices are also widely indicated for patients with heart failure. ${ }^{17}$ The initial focus was on implantable cardiac defibrillators $(I C D s)^{18,19}$ to try to reduce arrhythmic deaths, and ventricular assist devices (VADs) ${ }^{20-22}$ to support the heart. More recently, atrio-biventricular pacemakers, otherwise called cardiac resynchronisation therapy (CRT) devices, have been shown to have striking benefits for patients with heart failure. ${ }^{18,23-26}$ This article will focus on ICDs, CRT devices and their combination (CRT-D).

\section{IMPLANTABLE DEFIBRILLATORS}

Current guidelines suggest that ICDs should be deployed widely in patients with severe chronic LV dysfunction, but vary in their recommendations about seeking additional evidence of risk from fatal arrhythmias (Table I). ${ }^{27-33}$

These guidelines are based on a series of studies focused on secondary (i.e. patients who have had a symptomatic ventricular arrhythmia) ${ }^{3437}$ and primary (patients who have not had a symptomatic episode) prevention of sudden death, which have produced rather modest results (Tables 2A and 2B). ${ }^{19,38-43}$ For secondary prevention, compared with anti-arrhythmic therapy that might actually have an adverse effect on prognosis, ${ }^{19,4}$ ICDs will save about seven lives over the first year for every 100 devices implanted in the best-performing trial, ${ }^{34}$ with a sustained but not growing benefit thereafter. However, patients with an LVEF $>40 \%$ and those aged $>75$ years derived no benefit, due to a propensity to die of things other than arrhythmias. ${ }^{37,45}$ For primary prevention, for every 100 ICDs implanted into patients with chronic LV dysfunction, one or two deaths will be prevented each year. ${ }^{46}$ Over a ten-year period this is a substantial effect, but for patients who have a life-expectancy of less than five years due to other diseases the effect could be considered rather small. ${ }^{47}$ Although ICDs may reduce sudden death if implanted within the first few weeks after an Ml, they appear to accelerate death from other causes, possibly heart failure, and have no overall effect on mortality. ${ }^{48-50}$ On the other hand, the MADIT-II trial ${ }^{43}$ suggests that late implantation of an ICD months or years after an $\mathrm{MI}$ in patients with an LVEF $<30 \%$ is moderately effective at reducing all-cause mortality.

There are probably several reasons for the failure of ICDs to have a large impact on survival. Most importantly, although ICDs reduced sudden death, many patients go on to die of heart failure. It is even possible that ICDs accelerate this process, either because of right ventricular (RV) pacing or because of myocardial damage associated with defibrillator shocks. ${ }^{51}$ Adverse effects on the remodelling of 'soft' myocardial scarring after an MI may account for the lack of effect of ICD implantation shortly after an MI, even though it reduces arrhythmic death. ${ }^{48,4,52}$ As noted above, many patients with heart 
TABLE 2A Summary of multi-centre randomised controlled trials of implantable cardioverter defibrillators. (The COMPANION trial is included in Table 4A. MUSTT ${ }^{44}$ was not truly a randomised trial of ICDs and is excluded.)

\begin{tabular}{|c|c|c|c|c|c|c|c|}
\hline \multicolumn{8}{|c|}{ Primary prevention trials in patients with chronic left ventricular dysfunction } \\
\hline & DEFINITE ${ }^{38}$ & AMIOVIRT $^{39}$ & CAT $^{40}$ & SCD-HeFT'19 & $\begin{array}{l}\text { CABG } \\
\text { Patch }\end{array}$ & MADIT $^{42}$ & $\begin{array}{l}\text { MADIT } \\
\text { II }^{43}\end{array}$ \\
\hline IHD (\%) & Excluded & Excluded & Excluded & 58 & 100 & 100 & 100 \\
\hline Recent MI (\%) & Excluded & Excluded & Excluded & Rare & Rare & 25 & 12 \\
\hline Median duration (months) & 29 & 24 & 66 & 45.5 & 32 & 37 & 20 \\
\hline Total number $(\mathrm{n})$ & 458 & 103 & $104^{*}$ & 2,521 & 900 & 196 & 1,232 \\
\hline Control group (n) & 229 & 52 & 54 & $847 / 845^{\pi}$ & 454 & 92 & 490 \\
\hline Medical treatment & Standard ${ }^{\dagger}$ & Amiodarone & Standard ${ }^{\dagger}$ & $\begin{array}{l}\text { Placebo/ } \\
\text { amiodarone }\end{array}$ & Standard ${ }^{\dagger}$ & Standard ${ }^{\dagger}$ & Standard ${ }^{\dagger}$ \\
\hline LVEF $(\%)^{\ddagger}$ & $\leq 36 / 21$ & $\leq 35 / 23$ & $\leq 30 / 24$ & $\leq 35 / 25$ & $\leq 36 / 27$ & $\leq 35 / 26$ & $\leq 30 / 23$ \\
\hline Age (years) & 58 & 60 & 52 & 60 & 64 & 63 & 65 \\
\hline $\begin{array}{l}\text { Additional evidence of } \\
\text { arrhythmia risk required? }\end{array}$ & $\begin{array}{l}\text { Yes (NSVT } \\
\text { orVES) }\end{array}$ & Yes (NSVT) & No & $\begin{array}{l}\text { No (but NSVT } \\
\text { present in } 23 \% \\
\text { and cardiac } \\
\text { syncope in } 6 \% \text { ) }\end{array}$ & $\begin{array}{l}\text { Yes } \\
\text { (SAECG) }\end{array}$ & Yes (EP) & No \\
\hline Heart failure (\%) & 100 & 100 & 100 & 100 & 50 & 51 & $\sim 75$ \\
\hline NYHA class & $22 / 57 / 21 / 0$ & $13 / 63 / 24 / 0$ & $0 / 65 / 35 / 0$ & $0 / 70 / 30 / 0$ & $27 / 73 / 0$ & $65 \%$ in II/III & $36 / 35 / 29 / 0$ \\
\hline $\begin{array}{l}\text { Were subjects taking } \\
\text { AA drug class I? }\end{array}$ & No & No & No & No & Yes (15\%) & NA & Yes (3\%) \\
\hline $\begin{array}{l}\text { Patients taking beta } \\
\text { blockers (\%) }\end{array}$ & 85 & 51 & 3.8 & 69 & 21 & 34 & 70 \\
\hline $\begin{array}{l}\text { Was all-cause mortality } \\
\text { significantly reduced? }\end{array}$ & No & No & No & Yes & No & Yes & Yes \\
\hline $\begin{array}{l}\text { Was arrhythmic death } \\
\text { significantly reduced? }\end{array}$ & Yes & No & No & Yes & No & Yes & Yes \\
\hline
\end{tabular}

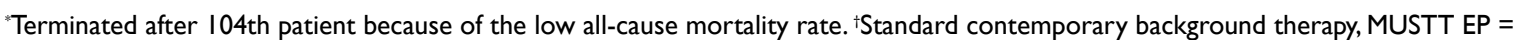
Electrophysiology test guided therapy (la,Amiodarone, Sotalol). ${ }^{\ddagger}$ Numbers given are those for the entry criterion and the mean or median value at baseline. "Conventional therapy + placebo or amiodarone or defibrillator. "NYHA class shown as percentage in class I/ II/III/IV, in case of CABG Patch NYHA I/II-III/IV. Abbreviations: AA = anti-arrhythmic; electrophysiology test-guided therapy (la, amiodarone, sotalol); ICD = implantable cardioverter defibrillator; IHD = ischaemic heart disease; LVEF = left ventricular ejection fraction; $M I=$ myocardial infarction; NA = not available; NSVT = non-sustained ventricular tachycardia; NYHA = New York Heart Association classification; SAECG $=$ abnormal signal-averaged electrocardiogram;VES = ventricular extrasystole.

failure are elderly and have many other potentially fatal co-morbid diseases. Although an ICD may reduce arrhythmic deaths, it will do nothing to prevent death due to respiratory or renal disease. ${ }^{45}$ ICDs generally have little or no benefit when implanted in patients aged $>75$ years, ${ }^{45}$ although in carefully selected patients there is a sparse amount of evidence indicating benefit..$^{53}$

Implantable cardiac defibrillators are expensive and associated with substantial morbidity, ${ }^{54}$ including the risks of implantation, device infection and malfunction, inappropriate shocks (i.e. shocks delivered due to false detection of an arrhythmia) or appropriate but unnecessary shocks (i.e. shocks given for a ventricular arrhythmia that would have self-terminated if left alone) and the need for replacement every few years, a procedure that carries appreciable risk. Many shocks are painful although some patients are oblivious to them, not even waking from sleep. Moreover, ICDs rarely provide symptomatic benefit, although anti-tachycardia pacing functions can reduce the symptoms associated with arrhythmias. Technological advances may reduce these risks. Conceptual advances may make an even bigger contribution. Just making the devices hesitate before intervening may reduce the rate of shocks by $>75 \% .{ }^{47}$

Patients with severe LV systolic dysfunction who are relatively young and with few co-morbidities (already a lower-risk population) have an extraordinarily low mortality if also managed with an ICD. ${ }^{18}$ In other words, if the LV is sick and the patient is well then ICDs appear to exert a powerful benefit. On the other hand, for patients with moderately severe heart failure, ICDs are associated with little or no benefit. ${ }^{19}$ However, as treatment for heart failure and other chronic diseases improves, so the importance of reducing arrhythmic death may increase and so smaller, safer and less expensive devices should be developed. 
TABLE 2B Summary of multi-centre randomised controlled trials of implantable cardioverter defibrillators

\begin{tabular}{|c|c|c|c|c|c|c|}
\hline & \multicolumn{3}{|c|}{$\begin{array}{l}\text { Primary prevention after myocardial } \\
\text { infarction }\end{array}$} & \multicolumn{3}{|c|}{ Secondary prevention } \\
\hline & DINAMIT ${ }^{48}$ & IRIS ${ }^{49}$ & BEST-ICD ${ }^{50}$ & CIDS $^{35}$ & CASH $^{36}$ & AVID $^{34}$ \\
\hline IHD (\%) & 100 & 100 & 100 & 83 & 75 & 82 \\
\hline Recent MI & $6-40$ days & $5-31$ days & $5-30$ days & $\begin{array}{l}\text { Excluded within } \\
3 \text { days }\end{array}$ & $\begin{array}{l}\text { Excluded within } \\
3 \text { days }\end{array}$ & $\begin{array}{l}\text { Excluded } \\
\text { within } 5 \text { days }\end{array}$ \\
\hline Median duration (months) & 30 & 37 & 17 & 36 & 57 & 22 \\
\hline Total number (n) & 674 & 898 & 143 & 659 & 288 & 1,016 \\
\hline Control group (n) & 342 & 453 & 59 & 331 & $92 / 97$ & 509 \\
\hline Medical treatment & Standard* & Standard* & $\begin{array}{l}\text { Metoprolol/ } \\
\mathrm{EP}^{\dagger}\end{array}$ & Amiodarone & $\begin{array}{l}\text { Amiodarone/ } \\
\text { Metoprolol/ } \\
\text { Propafenone }\end{array}$ & Amiodarone \\
\hline LVEF (\%) $)^{\ddagger}$ & $\leq 35 / 28$ & $\leq 40 / 35$ & $\leq 35 / 31$ & Mean 34 & Mean 45 & Mean 32 \\
\hline Age (years) & 62 & 62 & 66 & 63 & 58 & 66 \\
\hline $\begin{array}{l}\text { Cardiac arrest or cardiac } \\
\text { syncope }\end{array}$ & $\begin{array}{l}\text { Excluded }>48 \\
\text { hours post } \mathrm{MI}\end{array}$ & Excluded & $\begin{array}{l}\text { SCD only } \\
\text { due to VF }\end{array}$ & $75 \%$ & $100 \%$ & $66 \%$ \\
\hline Symptomatic VT & Excluded & Excluded & Excluded & $38 \%$ & $100 \%$ & $55 \%$ \\
\hline $\begin{array}{l}\text { Additional evidence of } \\
\text { arrhythmia risk required? }\end{array}$ & $\begin{array}{l}\text { Yes ( } \downarrow \text { HRV or } \\
\uparrow H R)\end{array}$ & $\begin{array}{l}\text { Yes (NSVT } \\
\text { or } \uparrow \mathrm{HR} \text { ) }\end{array}$ & $\begin{array}{l}\text { Yes ( } \downarrow H R V, \\
\text { SAECG or } \\
\text { VES) }\end{array}$ & $\begin{array}{l}\text { EP if enrolled due } \\
\text { to unexplained } \\
\text { syncope ( } 14 \% \text { of } \\
\text { patients) }\end{array}$ & No & No \\
\hline Heart failure (\%) & 48 & 45 & $\mid I+5 I^{\pi}$ & 50 & NA & 57 \\
\hline NYHA class** & $13 / 60 / 27 / 0$ & $28 / 60 / 12 / 0.1$ & NA & $39 / 11$ & $27 / 57 / 16 / 0$ & $48 / 9$ \\
\hline $\begin{array}{l}\text { Were subjects taking AA } \\
\text { drug class I? }\end{array}$ & No & No & No & Yes (8\%) & $\begin{array}{l}\text { Propafenone } \\
\text { arm terminated } \\
\text { early }\end{array}$ & No \\
\hline $\begin{array}{l}\text { Patients taking beta } \\
\text { blockers (\%) }\end{array}$ & 87 & 96 & 100 & 76 & $0 / 0 / 99^{t+}$ & 59 \\
\hline $\begin{array}{l}\text { Was all-cause mortality } \\
\text { significantly reduced? }\end{array}$ & No & No & No & No & No & Yes \\
\hline $\begin{array}{l}\text { Was arrhythmic death } \\
\text { significantly reduced? }\end{array}$ & Yes & Yes & No & No & Yes & Yes \\
\hline
\end{tabular}

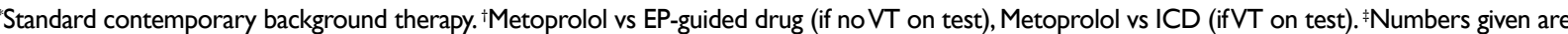
those for the entry criterion and the mean or median value at baseline. "History of heart failure + heart failure in coronary care unit." NYHA class shown as percentage in class I/ II/III/IV, in case of CIDS and AVID NYHA I-II/III-IV. "Beta blockers used in the ICD, amiodarone and metoprolol groups, respectively. Abbreviations:AA = anti-arrhythmic; $\mathrm{EP}=$ electrophysiology test-guided therapy (la, amiodarone, sotalol); $\mathrm{HR}=$ elevated heart rate on 24-hour tape recording; $H R V=$ depressed heart rate variability; ICD = implantable cardioverter defibrillator; IHD = ischaemic heart disease; $L V E F=$ left ventricular ejection fraction; $\mathrm{MI}=$ myocardial infarction; $\mathrm{NA}=$ not available; NSVT = non-sustained ventricular tachycardia; NYHA = New York Heart Association classification; $\mathrm{SAECG}=$ abnormal signal averaged electrocardiogram; $\mathrm{SCD}=$ sudden cardiac death;VES = ventricular extrasystole; $\mathrm{VF}=$ ventricular fibrillation; $\mathrm{VT}=$ ventricular tachycardia.

One potential lower-cost solution for defibrillation is a subcutaneous ICD, which is simpler and safer to implant and requires less skill. ${ }^{55}$ However, this change in technology raises some fundamental concerns about the mechanism of action of ICDs. It is assumed that since ICDs are designed to deliver shocks to treat ventricular tachyarrhythmias, this must be their mechanism of benefit. However, brady-arrhythmias may be as or more lethal in this population and, presumably, require only pacing. ${ }^{47,56-58}$ It is possible that it is the pacing function of ICDs that is the key to their success. Indeed, the only study to compare pacing alone to pacing with an ICD failed to show a difference. ${ }^{25}$ Subcutaneous defibrillators do not have a pacing function and so their efficacy cannot be assumed.

\section{CARDIAC RESYNCHRONISATION THERAPY}

Current guidelines recommend the use of CRT only in selected groups of patients with heart failure with advanced symptoms, severe LV systolic dysfunction and with a broad QRS complex (Table 3). Recommendations on patient selection reflect the selection criteria applied in clinical trials rather than identification of groups of patients that did not benefit from CRT.You cannot prove that something does not work until you show it does not work! 
TABLE 3 Guidelines for cardiac resynchronisation therapy

\begin{tabular}{|c|c|c|c|c|}
\hline & $\mathrm{NICE}^{27}$ & SIGN $^{28}$ & $\begin{array}{l}\text { ESC } \\
\text { Heart } \\
\text { Failure }^{29}\end{array}$ & $\begin{array}{l}\text { ACCFI } \\
\text { AHA } \\
\text { Heart } \\
\text { Failure }^{30}\end{array}$ \\
\hline NYHA & III-IV & III-IV & III-IV & III-IV \\
\hline $\begin{array}{l}\text { Ejection } \\
\text { fraction }\end{array}$ & $\leq 35 \%$ & $\leq 35 \%$ & $\leq 35 \%$ & $\leq 35 \%$ \\
\hline $\begin{array}{l}\text { QRS } \\
\text { duration }\end{array}$ & $\begin{array}{l}\geq 150 \mathrm{~ms} \\
\text { or } 120- \\
149 \mathrm{~ms}^{*}\end{array}$ & $>120 \mathrm{~ms}$ & $\geq 120 \mathrm{~ms}$ & $\geq 120 \mathrm{~ms}$ \\
\hline Rhythm & Sinus & Sinus & $\begin{array}{l}\text { No require- } \\
\text { ments }\end{array}$ & $\begin{array}{l}\text { Sinus } \\
\text { or } \mathrm{AF}^{* * * *}\end{array}$ \\
\hline $\begin{array}{l}\text { Pharmaco- } \\
\text { therapy } \\
\text { requirement }\end{array}$ & 'Optimal' & $\begin{array}{l}\text { 'Drug } \\
\text { refractory } \\
\text { symptoms' }\end{array}$ & 'Optimal' & 'Optimal' \\
\hline
\end{tabular}

"Mechanical dyssynchrony confirmed by echocardiography also required. "Class I recommendation. "Class lla recommendation.

Abbreviations: $\mathrm{ACCF}=$ American College of Cardiology Foundation; $\mathrm{AF}=$ atrial fibrillation; $\mathrm{AHA}=$ American Heart Association; $\mathrm{ESC}$ = European Society of Cardiology; NICE = National Institute for Health and Clinical Excellence; NYHA = New York Heart Association classification; SIGN = Scottish Intercollegiate Guidelines Network

In contrast to the trials of ICDs, trials of CRT have been uniformly successful when adequately powered (Tables $4 \mathrm{~A}$ and $4 \mathrm{~B}) .^{18,23-26,59-66}$ This is of some concern because the observed large and consistent benefits suggest that the inclusion/exclusion criteria in these trials may have been too narrow. Once the effects of crossovers are factored in, CRT may halve mortality, with an absolute reduction in mortality of about $20 \%$ over three years. ${ }^{24}$ In other words, the effect of CRT may be about three times greater than an ICD.

Cardiac resynchronisation therapy devices are relatively low in cost. The LV lead requires skill to implant and lead displacement is common, although technological advances are reducing both these problems. ${ }^{54,67}$ Otherwise, the morbidity associated with these devices is much lower than with ICDs and they have the potential to improve cardiac function and symptoms, sometimes dramatically. 18,24,26,68,69 Three recent analyses suggest that CRT reduces morbidity and mortality even in patients with few or no symptoms. ${ }^{18,26,70}$ Indeed, patients with mild to moderate symptoms and less severe cardiac dysfunction may gain the greatest benefit from CRT device implantation. ${ }^{71}$

As with ICDs there is considerable confusion about how CRT works. The conventional wisdom is that CRT resynchronises uncoordinated ventricular function. However, all the large CRT trials studied only patients in sinus rhythm and shortened the atrioventricular (AV) delay to maximise LV preload and reduce diastolic mitral regurgitation. ${ }^{17,72}$ Cardiac resynchronisation therapy can also reduce systolic mitral regurgitation, ${ }^{69}$ presumably by improving the timing of papillary muscle activation. The hallmark of improved cardiac performance with CRT is a rise in systolic blood pressure. ${ }^{25,64}$ Interestingly, it is the timing of AV stimulation rather than RV/LV stimulation that makes the largest difference to blood pressure. ${ }^{73}$ Low blood pressure is an ominous prognostic sign and predicts a greater effect of CRT on morbidity and mortality. ${ }^{74}$ Moreover, attempts to predict benefit based on ventricular dyssynchrony have met with little success, ${ }^{75,76}$ and the PR interval rather than the QRS duration may be the better predictor of benefit from CRT. ${ }^{77}$

Perhaps most telling of all is the dissociation between the effects of CRT on cardiac function and clinical outcome. ${ }^{75,78}$ Improvement in cardiac function three months after implant explains very little of the long-term benefit of $\mathrm{CRT}^{75}$ Patients with ischaemic heart disease have more LV scarring and, as expected and observed for other interventions, ${ }^{79} \mathrm{LV}$ function improves less with CRT compared to patients with dilated cardiomyopathy. ${ }^{78}$ However, patients with ischaemic heart disease get a somewhat greater reduction in mortality. Cardiac resynchronisation therapy is exerting effects in ways other than improved cardiac function. Indeed, CRT reduces the risk of sudden death either by preventing fatal brady- or tachyarrhythmias..$^{24,80}$ The concept that pacing alone can prevent ventricular tachycardia is not new. ${ }^{81-84}$

When interpreting reports investigating the relationship between clinical and imaging characteristics and CRT technology it is important to distinguish between the concepts of outcome and response. ${ }^{72}$ Observational trials cannot distinguish between response and outcome; that requires a controlled, preferably randomised, trial. Observational studies of CRT are confounded by at least two specific, major problems. Firstly, for any given LVEF, patients with dyssynchrony will have a better outcome even if they do not get CRT. ${ }^{75,76,85}$ This is perfectly logical. If the LVEF is $30 \%$ and there is no dyssynchrony, then it is a 'real' value. On the other hand, if dyssynchrony is present, the sum of regional EFs will be $>30 \%$. Dyssynchrony is a sign of viability. ${ }^{86}$ The second major problem is that, as noted above, improvement in LVEF is a poor surrogate for the clinical benefits of CRT. The aetiology of LV damage is the major determinant of whether LVEF will improve. ${ }^{78}$ Observational trials should always show that patients with dyssynchrony do better and patients with ischaemic heart disease do worse, regardless of whether they get CRT or not. Randomised controlled trials are the only rigorous way of evaluating the response to therapy.

\section{CARDIAC RESYNCHRONISATION DEVICES WITH A DEFIBRILLATOR FUNCTION}

The assumption from guidelines is that CRT-D is the sum of its constituent parts, CRT and ICD. It is not clear that this is true. Cardiac resynchronisation therapy could make ICDs work much better because it reduces the risk of 
TABLE 4A Summary of multi-centre randomised controlled trials of cardiac resynchronisation therapy

\begin{tabular}{|c|c|c|c|c|c|c|c|}
\hline & \multicolumn{2}{|l|}{ MUSTIC } & \multirow[t]{2}{*}{ CONTAK $^{62}$} & \multicolumn{3}{|c|}{ MIRACLE } & \multirow[t]{2}{*}{ COMPANION $^{25}$} \\
\hline & Sinus $^{60}$ & $\mathbf{A F}^{61}$ & & CRT $^{23}$ & $I^{\prime C D}{ }^{63}$ & ICD-II ${ }^{64}$ & \\
\hline Blinded & Single & Single & Double & Double & Double & Double & No \\
\hline Median duration (months) & 3 (X-over) & 3 (X-over) & $3-6$ & 6 & 6 & 6 & $12-16$ \\
\hline Total number $(\mathrm{n})$ & \multicolumn{2}{|l|}{131} & 490 & 453 & 369 & 186 & 1,520 \\
\hline Control group (n) & 67 (X-over) & 64 (X-over) & 245 & 225 & 182 & 101 & 308 \\
\hline ICD required? & No & No & Yes & No & Yes & Yes & In one group only \\
\hline Age (years) & 64 & 65 & 66 & 64 & 67 & 63 & 67 \\
\hline Sinus rhythm & Yes & No & Yes & Yes & Yes & Yes & Yes \\
\hline QRS (ms)* & $>150 / 174$ & $>200 / 209$ & $>120 / 160$ & $>130 / 165$ & $>130 / 165$ & $>130 / 166$ & $>120 / 160$ \\
\hline Dyssynchrony required? & \multicolumn{2}{|l|}{ No } & No & \multicolumn{3}{|l|}{ No } & No \\
\hline LVEF (\%)* & $<35 / 23$ & $<35 / 26$ & $<35 / 21$ & $<35 / 22$ & $<35 / 24$ & $<35 / 24$ & $<35 / 20$ \\
\hline NYHA class ${ }^{\dagger}$ & $0 / 100 / 0$ & $0 / 100 / 0$ & $32 / 60 / 8$ & $0 / 90 / 10$ & $0 / 88 / 12$ & $100 / 0 / 0$ & $0 / 87 / 13$ \\
\hline Median QoL & 47 & 44 & 42 & 59 & 56 & 41 & 39 \\
\hline IHD (\%) & $\sim 37$ & NA & 67 & 50 & 64 & 55 & 54 \\
\hline ACE inhibitor (\%) & 96 & 100 & 86 & 93 & 93 & 98 & 89 \\
\hline Beta blocker (\%) & 28 & 23 & 48 & 62 & 62 & 64 & 68 \\
\hline Spironolactone (\%) & 22 & 16 & NA & NA & NA & NA & 53 \\
\hline Improvement in LV function & NA & NA & Yes & Yes & Borderline & Yes & NA \\
\hline Improvement in symptoms & NA & NA & $\mathrm{No}^{t t}$ & Yes & Yes & Yes & Yes \\
\hline $\begin{array}{l}\text { Improvement in exercise } \\
\text { capacity }\end{array}$ & Yes & No & Yes & Yes & Equivocal & No & Yes \\
\hline Improvement in QoL & Yes & No & $\mathrm{No}^{t t}$ & Yes & Yes & No & Yes \\
\hline $\begin{array}{l}\text { Reduction in hospitalisation } \\
\text { for HF }\end{array}$ & Yes & No & No & Yes & No & No & Yes \\
\hline Improvement in CCS & NA & NA & NA & NA & NA & NA & NA \\
\hline Improvement in mortality & $\begin{array}{l}\text { Not } \\
\text { powered to } \\
\text { assess }\end{array}$ & $\begin{array}{l}\text { Not } \\
\text { powered to } \\
\text { assess }\end{array}$ & $\begin{array}{l}\text { Not } \\
\text { powered to } \\
\text { assess }\end{array}$ & $\begin{array}{l}\text { Not } \\
\text { powered } \\
\text { to assess }\end{array}$ & $\begin{array}{l}\text { Not } \\
\text { powered } \\
\text { to assess }\end{array}$ & $\begin{array}{l}\text { Not } \\
\text { powered } \\
\text { to assess }\end{array}$ & Yes \\
\hline
\end{tabular}

'X-over' means crossover design, and numbers shown are the number of patients who entered the first phase of the study. Other studies used a parallel group design. "Numbers given are those for the entry criterion and the mean or median value at baseline. ${ }^{\dagger} \mathrm{NYHA}$ class is shown as percentage in class I or II/III/IV. ${ }^{* *}$ Quality of life $(\mathrm{Q} O \mathrm{~L})$ assessed using the Minnesota Living with Heart Failure instrument. Abbreviations: $A C E=$ angiotensin-converting enzyme; CCS = clinical composite score (including all-cause mortality, HF hospitalisation, NYHA class and global assessment); $\mathrm{HF}=$ heart failure; $I C D=$ implantable cardioverter defibrillator; $I H D=$ ischaemic heart disease; $L V=$ left ventricular; $L V E F=$ left ventricular ejection fraction; NA = not available; NYHA = New York Heart Association; $\mathrm{QoL}=$ quality of life

dying from heart failure. Even though CRT reduces the rate of sudden death, the proportion of the deaths that are sudden may increase because it is even more effective at reducing death due to worsening heart failure. On the other hand, many sudden deaths may be due to bradyarrhythmias that are adequately treated by pacing, and CRT may also improve ventricular function and suppress tachyarrhythmias. ${ }^{56-58}$ These effects could reduce the role of adding an ICD function to a CRT device.

The only trial to compare CRT and CRT-D head-to-head is COMPANION, ${ }^{25}$ in which patients assigned to CRT-D had the lowest mortality - but not significantly less than with CRT alone. Benefits in terms of a rise in blood pressure, improved symptoms and increased exercise capacity were similar with CRT and CRT-D. Extrapolation from this study and from CARE-HF suggest that
$75 \%$ of the benefits of CRT-D are delivered by the CRT component. ${ }^{87,88}$

\section{SHOULD ALL HEART FAILURE PATIENTS WHO ARE ABOUT TO RECEIVE AN ICD GET CRT-D?}

On present evidence it is hard to justify implanting an ICD rather than a CRT-D device into a patient who has heart failure and important LV systolic dysfunction. Heart failure is a progressive disease: the QRS gets wider with time, ${ }^{89,90}$ ventricular function is likely to deteriorate and symptoms progress. The patient may not need CRT at the time of implant but runs a high risk of needing it before the device needs to be replaced. As these devices are expensive and replacement entails morbidity and mortality, there is a strong argument for the default position of implanting a CRT-D device unless 
TABLE 4B Summary of multi-centre randomised controlled trials of cardiac resynchronisation therapy

\begin{tabular}{|c|c|c|c|c|c|c|}
\hline & \multicolumn{2}{|c|}{ CARE-HF } & \multirow[t]{2}{*}{ RETHINQ $^{66}$} & \multirow[t]{2}{*}{ MADIT CRT ${ }^{18}$} & \multicolumn{2}{|l|}{ REVERSE } \\
\hline & Main $^{65}$ & Extension $^{24}$ & & & Main $^{67}$ & Extension $^{26}$ \\
\hline Blinded & \multicolumn{2}{|l|}{ No } & Double & Double & \multicolumn{2}{|l|}{ Double } \\
\hline Median duration (months) & 30 & 37 & 6 & 2.4 & 12 & 24 \\
\hline Total number $(\mathrm{n})$ & \multicolumn{2}{|l|}{813} & 172 & 1,820 & 610 & 262 \\
\hline Control group (n) & \multicolumn{2}{|l|}{404} & 85 & 731 & 191 & 82 \\
\hline ICD required? & \multicolumn{2}{|l|}{ No } & Yes & Yes & \multicolumn{2}{|l|}{ Yes } \\
\hline Age (years) & \multicolumn{2}{|l|}{67} & 59 & 65 & 62 & 61 \\
\hline Sinus rhythm & \multicolumn{2}{|l|}{ Yes } & Yes & Yes & \multicolumn{2}{|l|}{ Yes } \\
\hline QRS (ms)* & \multicolumn{2}{|c|}{$>120 / 160$} & $<130 / 106$ & $>130 / \mathrm{NA}$ & $>120 / 153$ & $>120 / 156$ \\
\hline Echo for dyssynchrony required? & \multicolumn{2}{|c|}{ Only if QRS I20-149 ms } & Yes & No & \multicolumn{2}{|l|}{ No } \\
\hline LVEF (\%)* & \multicolumn{2}{|l|}{$<35 / 25$} & $<35 / 25$ & $<30 / 24$ & $<40 / 26$ & $<40 / 28$ \\
\hline NYHA class ${ }^{\dagger}$ & \multicolumn{2}{|c|}{$0 / 94 / 6\left(23 / 65 / I I^{\dagger}\right)$} & $0 / 100 / 0$ & $100 / 0 / 0$ & \multicolumn{2}{|l|}{$100 / 0 / 0$} \\
\hline Median QoL* & \multicolumn{2}{|l|}{44} & 55 & NA & 28 & 26 \\
\hline IHD (\%) & \multicolumn{2}{|l|}{40} & 53 & 55 & 54 & 43 \\
\hline ACE inhibitor (\%) & \multicolumn{2}{|l|}{95} & 90 & 97 & 96 & 99 \\
\hline Beta blocker (\%) & \multicolumn{2}{|l|}{70} & 95 & 93 & 95 & 93 \\
\hline Spironolactone (\%) & \multicolumn{2}{|l|}{54} & NA & 31 & \multicolumn{2}{|l|}{ NA } \\
\hline \multicolumn{7}{|l|}{ Improvement in: } \\
\hline LV function & Yes & NA & No & Yes & Yes & Yes \\
\hline Symptoms & Yes & NA & Yes & NA & Yes & Yes \\
\hline Exercise capacity & NA & NA & No & NA & No & No \\
\hline QoL & Yes & NA & No & NA & No & No \\
\hline Hospitalisation for HF & Yes & NA & NA & Yes & Yes & Yes \\
\hline CCS & NA & NA & NA & NA & No & Yes \\
\hline Mortality & Yes & Yes & $\begin{array}{l}\text { Not powered to } \\
\text { assess }\end{array}$ & No & $\begin{array}{l}\text { Not powered } \\
\text { to assess }\end{array}$ & Yes \\
\hline
\end{tabular}

Numbers given are those for the entry criterion and the mean or median value at baseline. ${ }^{+}$Physician-reported NYHA class shown as a percentage in class I or II/III/IV. "Quality of life (QoL) assessed using the Minnesota Living with Heart Failure instrument. Abbreviations: ACE = angiotensin-converting enzyme; $\mathrm{CCS}=$ clinical composite score (including all-cause mortality, HF hospitalisation, NYHA class and global assessment); $\mathrm{HF}=$ heart failure; ICD = implantable cardioverter defibrillator; IHD = ischaemic heart disease; $L V=$ left ventricular; $L V E F=$ left ventricular ejection fraction; NA = not available; NYHA = New York Heart Association; QoL = quality of life.

there are good reasons not to. Less expert implanters may decide to implant a CRT-D device without the LV lead with the intention of upgrading when needed, since LV lead displacement is the major added complication of implanting a CRT-D rather than ICD alone. Expert implanters should consider implanting a fully functioning system and reduce the ventricular pacing to a back-up mode if activation causes a decline in blood pressure or worsening cardiac function or symptoms.

The evidence that QRS width is an important predictor of clinical benefit with CRT is controversial, ${ }^{18,26,75,76}$ especially when hard outcomes, such as death, are considered. Studies suggesting a link between QRS duration and improvement in ventricular function with CRT should be interpreted with caution in view of the fact that changes in ventricular function are a poor indicator of long-term clinical benefit. Since we have no evidence that any segment of the population does not benefit from CRT, and because the CRT function can be programmed on and off at will, it is difficult to find a good argument, other than operator skill and perhaps lead displacement, not to prefer implanting a CRT-D device rather than an ICD.

\section{WHICH HEART FAILURE PATIENTS WHO HAVE AN INDICATION FOR CRT SHOULD HAVE CRT-D?}

Most of the benefit of CRT-D is delivered by the CRT component. ${ }^{88}$ Patients selected for CRT-D should be at low risk of dying from lung, renal or other non-cardiac disease, with the hope that CRT will reduce the risk of dying from heart failure and the ICD component will deal with any ventricular arrhythmias not prevented by CRT. Age is an important indicator of dying from co-morbid disease and therefore the wisdom of implanting a CRT-D device in patients aged $>75$ years is of particular concern. ${ }^{45,53}$ 


\section{REMOTE MONITORING}

Many implanted devices are now enabled for remote monitoring, either to check on how the device is performing and so replace routine hospital visits, or to monitor the patient. ${ }^{91,92}$ A great variety of patientmonitoring technologies are available, ranging from recording physical activity, arrhythmias, heart rate, heart rate variability and thoracic fluid impedance to cardiac pressures and flow. The ability to monitor device function remotely is designed to improve care rather than outcomes, although detection of device faults (rare events) can reduce morbidity and save lives. There is considerable evidence that non-invasive monitoring can reduce mortality. ${ }^{93,94}$ There is every expectation that implanted monitors can too.

\section{REFERENCES}

I Torabi A, Rigby AS, Cleland JG. Declining in-hospital mortality and increasing heart failure incidence in elderly patients with first myocardial infarction.J Am Coll Cardiol 2009;55:79-8I . doi: I 0.1016/j. jacc.2009.05.080

2 Torabi A, Cleland JG, Khan NK et al. The timing of development and subsequent clinical course of heart failure after a myocardial infarction. Eur Heart J 2008; 29:859-70. doi:I0.1093/eurheartj/ehn096

3 Cleland JG, Massie BM, Packer M. Sudden death in heart failure: vascular or electrical? Eur J Heart Fail 1999; I:4I-5. doi:10.1016/ SI388-9842(99)00009-4

4 Remme WJ, Cleland JG, Erhardt L et al. Effect of carvedilol and metoprolol on the mode of death in patients with heart failure. Eur J Heart Fail 2007; 9:I I28-35. doi:I0.1016/j.ejheart.2007.07.014

5 Cleland JG, Freemantle N, Ball SG et al. The heart failure revascularisation trial (HEART): rationale, design and methodology Eur J Heart Fail 2003; 5:295-303. doi:I0.I0I6/SI388-9842(03)00056-4

6 Coletta AP, Cleland JG, Cullington D et al. Clinical trials update from Heart Rhythm 2008 and Heart Failure 2008: ATHENA, URGENT, INH study, HEART and CK-1827452. Eur J Heart Fail 2008; 10:917-20. doi:10.1016/j.ejheart.2008.07.006

7 Cleland JGF, Orn S, Romo $M$ et al. Incidence, severity and timing of neurological events after a major myocardial infarction. Eur J Heart Fail 2003; 2(Suppl 2):8I-2. doi:I0.I0I6/SI567-42I5(03)90253-0

8 PROGRESS Collaborative Group. Randomised trial of a perindoprilbased blood-pressure-lowering regimen among 6105 individuals with previous stroke or transient ischaemic attack. Lancet 200I, 358:1033-4I. doi:I0.10I6/S0I40-6736(0I)06I78-5 Erratum in: Lancet 200I; 358:1556.

9 Amarenco P, Bogousslavsky J, Callahan A et al. High-dose atorvastatin after stroke or transient ischemic attack. N Engl J Med 2006; 355:549-59. doi:10.1056/NEJMoa06/894

10 Cleland JG. Is aspirin 'the weakest link' in cardiovascular prophylaxis? The surprising lack of evidence supporting the use of aspirin for cardiovascular disease. Prog Cardiovasc Dis 2002; 44:275-92. doi:10.1053/pcad.2002.31597

I I Cleland JG, McMurray JJ, Kjekshus J et al. Plasma concentration of amino-terminal pro-brain natriuretic peptide in chronic heart failure: prediction of cardiovascular events and interaction with the effects of rosuvastatin: a report from CORONA (Controlled Rosuvastatin Multinational Trial in Heart Failure). J Am Coll Cardiol 2009; 54:1850-9. doi:10.1016/j.jacc.2009.06.041

12 Poole-Wilson PA, Swedberg K, Cleland JG et al. Comparison of carvedilol and metoprolol on clinical outcomes in patients with chronic heart failure in the Carvedilol Or Metoprolol European Trial (COMET): randomised controlled trial. Lancet 2003; 362:713. doi:I0.10I6/S0|40-6736(03) I3800-7

\section{CONCLUSION}

The introduction of devices into the routine management of heart failure has improved symptoms and prognosis remarkably when used sensibly in selected patients. The treatment effect of CRT is so large that it is likely that many other groups of patients will benefit than have been studied so far. Adequately powered randomised trials of sufficient duration are required to address this issue. The potential of devices to modulate heart rate and myocardial contractility has not yet been fully established or exploited. The past decade has seen the introduction of ICDs and CRT into mainstream cardiology. Hopefully the next decade will help determine the limits of such therapy and the arrival of new technologies, such as ventricular assist devices, as part of the routine management of heart failure.

I3 Cleland JG, Rigby AS, McDonagh T et al. The National Audit of Heart Failure for England and Wales 2008-09. In submission.

I4 Bhatia RS, Tu JV, Lee DS et al. Outcome of heart failure with preserved ejection fraction in a population-based study. $N$ Engl J Med 2006; 355:260-9. doi:I0.1056/NEJMoa05I530

I5 Owan TE, Hodge DO, Herges RM et al. Trends in prevalence and outcome of heart failure with preserved ejection fraction. $N$ Engl J Med 2006; 355:25I-9. doi:10.1056/NEJMoa052256

16 Cleland JG, Tendera M, Taylor J. Prognosis in heart failure with a normal ejection fraction. N Engl J Med 2007; 357:829-30. doi:I0.1056/NEJMc076I79

17 Cleland JG, Nasir M, Tageldien A. Cardiac resynchronization therapy or atriobiventricular pacing - what should it be called? Nat Clin Pract Cardiovasc Med 2007; 4:90-101. doi:10.1038/ncpcardio0794

I8 Moss AJ, Hall WJ, Cannom DS et al. Cardiac-resynchronization therapy for the prevention of heart-failure events. $N$ Engl J Med 2009; 36I:1329-38. doi:I0.1056/NEJMoa090643 I

19 Bardy GH, Lee KL, Mark DB et al. Amiodarone or an implantable cardioverter-defibrillator for congestive heart failure. N Engl J Med 2005; 352:225-37. doi:10.1056/NEJMoa043399

20 Cleland JG, Coletta AP, Freemantle $\mathrm{N}$ et al. Clinical trials update from the American Heart Association Meeting 2009: HEAAL, FAIR-HF, J-CHF, HeartMate II and PACE. Eur J Heart Fail 2010; 12:197-201. doi:I0.1093/eurjhf/hfpI99

2I Rose EA, Gellins AC, Moskowitz AJ et al. Long-term use of a left ventricular assist device for end-stage heart failure. $N$ Engl J Med 200I; 345: I 435-43. doi:I0.I056/NEJMoa0I2I 75

22 Slaughter MS, Rogers JG, Milano CA et al. Advanced heart failure treated with continuous-flow left ventricular assist device. N Engl J Med 2009; 361:224|-5I. doi:I0.1056/NEJMoa0909938

23 Abraham WT, FisherWG, Smith AL et al. Cardiac resynchronization in chronic heart failure. $N$ Engl J Med 2002; 346:1845-53. doi: I0.1056/NEJMoa013168

24 Cleland JGF, Daubert J-C, Erdmann E et al. Longer-term effects of cardiac resynchronization therapy on mortality in heart failure [the CArdiac REsynchronization - Heart Failure (CARE-HF) trial extension phase]. Eur Heart J 2006; 27:1928-32. doi:10.1093/ eurheartj/ehl099

25 Bristow MR, Saxon LA, Boehmer J et al. Cardiac-resynchronization therapy with or without an implantable defibrillator in advanced chronic heart failure. New Engl J Med 2004; 350:2140-50. doi: 10.1056/NEJMoa032423

26 Daubert J-C, Gold MR, Abraham WT et al. Prevention of disease progression by cardiac resynchronization therapy in patients with asymptomatic or mildly symptomatic left ventricular dysfunction. J Am Coll Cardiol 2009;54:I837-46. doi:I0.1016/j.jacc.2009.08.0I I 
27 National Institute for Health and Clinical Excellence. TA I 20 Heart failure - cardiac resynchronisation: guidance. London: NICE; 2007. Available from: http://guidance.nice.org.uk/TAI20/Guidance/pdf/English

28 Scottish Intercollegiate Guidelines Network. Management of chronic heart failure. Edinburgh: SIGN; 2007. Available from: http:// www.sign.ac.uk/pdf/sign95.pdt

29 European Society of Cardiology, Heart Failure Association of the ESC (HFA), European Society of Intensive Care Medicine (ESICM) et al. ESC guidelines for the diagnosis and treatment of acute and chronic heart failure 2008: the Task Force for the diagnosis and treatment of acute and chronic heart failure 2008 of the European Society of Cardiology. Developed in collaboration with the Heart Failure Association of the ESC (HFA) and endorsed by the European Society of Intensive Care Medicine (ESICM). Eur J Heart Fail 2008; 10:933-89.

30 Jessup M, AbrahamWT, Casey DE et al. 2009 focused update: ACCF/ AHA Guidelines for the Diagnosis and Management of Heart Failure in Adults: a report of the American College of Cardiology Foundation/American Heart Association Task Force on Practice Guidelines: developed in collaboration with the International Society for Heart and Lung Transplantation. Circulation 2009; I 19:1977-2016.

3I National Institute for Health and Clinical Excellence. Arrhythmia implantable cardioverter defibrillators (ICDs). London: NICE; 2006. Available from: http://guidance.nice.org.uk/TA095

32 Scottish Intercollegiate Guidelines Network. Cardiac arrhythmias in coronary heart disease. Edinburgh: SIGN; 2007. Available from: http://www.sign.ac.uk/pdf/sign94.pdt

33 Zipes DP, Camm AJ, Borggrefe M et al. ACC/AHA/ESC 2006 Guidelines for Management of Patients with Ventricular Arrhythmias and the Prevention of Sudden Cardiac Death - executive summary: A report of the American College of Cardiology/American Heart Association Task Force and the European Society of Cardiology Committee for Practice Guidelines (Writing Committee to Develop Guidelines for Management of Patients with Ventricular Arrhythmias and the Prevention of Sudden Cardiac Death): developed in collaboration with the European Heart Rhythm Association and the Heart Rhythm Society. Eur Heart J 2006; 27:2099-140.

34 The antiarrhythmics versus implantable defibrillators (AVID) investigators. A comparison of antiarrhythmic drug therapy with implantable defibrillators in patients resuscitated from near-fatal ventricular arrhythmias. N Engl J Med 1997; 337:1576-83. doi:I0.1056/NEJMI997| I 273372202

35 Connolly SJ, Gent M, Roberts RS et al.Canadian Implantable Defibrillator Study (CIDS): a randomized trial of the implantable cardioverter defibrillator against amiodarone. Circulation 2000; 101:1297-302.

36 Kuck K-H, Cappato R, Siebels J et al. Randomized comparison of antiarrhythmic drug therapy with implantable defibrillators in patients resuscitated from cardiac arrest. The Cardiac Arrest Study Hamburg (CASH). Circulation 2000; 102:748-54.

37 Connolly SJ, Hallstrom AP, Cappato R et al. Meta-analysis of the implantable cardioverter defibrillator secondary prevention trials. Eur Heart J 2000; 21:207I-8. doi:I0.1053/euhj.2000.2476

38 Kadish A, Dyer A, Daubert JP et al. Prophylactic defibrillator implantation in patients with nonischemic dilated cardiomyopathy. N Engl J Med 2004; 350:2 I 5I-8. doi:I0.1056/NEJMoa033088

39 Strickberger SA, Hummel JD, Bartlett TG et al.Amiodarone versus implantable cardioverter-defibrillator: randomized trial in patients with nonischemic dilated cardiomyopathy and asymptomatic nonsustained ventricular tachycardia - AMIOVIRT. J Am Coll Cardiol 2003; 41:I707-12. doi:10.1016/S0735-1097(03)00297-3

40 Bänsch D, Antz M, Boczor S et al. Primary prevention of sudden cardiac death in idiopathic dilated cardiomyopathy: the Cardiomyopathy Trial (CAT). Circulation 2002; 105:|453-8. doi:I0.II6I/0I.CIR.00000I2350.997I8.AD

4I Bigger JT, for the Coronary Artery Bypass Graft (CABG) Patch trial investigators. Prophylactic use of implanted cardiac defibrillators in patients at high risk for ventricular arrhythmias after coronary-artery bypass graft surgery. N Engl J Med 1997; 337:1569-75. doi:I0.1056/NEJMI997| |27337220 I
42 Moss AJ, Hall WJ, Cannom DS et al. Improved survival with an implanted defibrillator in patients with coronary disease at high risk for ventricular arrhythmia. Multicenter Automatic Defibrillator Implantation Trial Investigators. N Engl J Med 1996; 335:1933-40. doi:I0.1056/NEJMI996I226335260I

43 Moss AJ, Zareba W, Hall WJ et al. Prophylactic implantation of a defibrillator in patients with myocardial infarction and reduced ejection fraction. N Engl J Med 2002; 346:877-83. doi:I0.1056/ NEJMoa0 3474

44 Buxton AE, Lee KL, DiCarlo $L$ et al. Electrophysiologic testing to identify patients with coronary artery disease who are at risk for sudden death. Multicenter Unsustained Tachycardia Trial Investigators. N Engl J Med 2000; 342:|937-45. doi:|0.1056/ NEJM200006293422602

45 Healey JS, Hallstrom AP, Kuck KH et al. Role of the implantable defibrillator among elderly patients with a history of lifethreatening ventricular arrhythmias. Eur Heart J 2007; 28: I 746-9. doi: I0.1093/eurheartj/ehl438

46 Cleland JG, Freemantle N, Kaye G et al. Clinical trials update from the American Heart Association meeting: omega-3 fatty acids and arrhythmia risk in patients with an implantable defibrillator, ACTIV in CHF, VALIANT, the Hanover autologous bone marrow transplantation study, SPORTIFV, ORBIT and PAD and DEFINITE. Eur J Heart Failure 2004; 6:109-15. doi:10.1016/j.ejheart.2003.12.002

47 Cleland JG, Buga L. Device therapy: defibrillators - a shocking therapy for cardiomyopathy? Nat Rev Cardiol 2010; 7:69-70. doi:10.1038/nrcardio.2009.233

48 Hohnloser SH, Kuck KH, Dorian P et al. Prophylactic use of an implantable cardioverter-defibrillator after acute myocardial infarction. N Engl J Med 2004; 35I:248I-8. doi:10.1056/ NEJMoa04I489

49 Steinbeck G, Andresen D, Seidl K et al. Defibrillator implantation early after myocardial infarction. N Engl J Med 2009; 36 I:|427-36. doi: 10.1056/NEJMoa0901889

50 Raviele A, Bongiorni MG, Brignole M. Early EPS/ICD strategy in survivors of acute myocardial infarction with severe left ventricular dysfunction on optimal beta-blocker treatment. The BEta-blocker STrategy plus ICD trial. Europace 2005; 7:327-37. doi:I0.1016/j. eupc.2005.03.003

5I Wilkoff BL, Cook JR, Epstein AE et al. Dual-chamber pacing or ventricular backup pacing in patients with an implantable defibrillator: the Dual Chamber and VVI Implantable Defibrillator (DAVID) trial. JAMA 2002; 288:3115-23. doi:10.100I/ jama.288.24.3115

52 Cleland JG, Coletta AP, Clark AL et al. Clinical trials update from the American College of Cardiology 2009: ADMIRE-HF, PRIMA, STICH, REVERSE, IRIS, partial ventricular support, FIX-HF-5, vagal stimulation, REVIVAL-3, pre-RELAX-AHF, ACTIVE-A, HF-ACTION, JUPITER, AURORA, and OMEGA. Eur J Heart Fail 2009; I I:622-30. doi:I0.1093/eurjhf/hfp07I

53 Huang DT, Sesselberg HW, McNitt S et al. Improved survival associated with prophylactic implantable defibrillators in elderly patients with prior myocardial infarction and depressed ventricular function: a MADIT-II substudy. J Cardiovasc Electrophysiol 2007; 18:833-8. doi: I0. I I I I/j. I540-8I67.2007.00857.x

54 Lee DS, Krahn AD, Healey JS et al. Evaluation of early complications related to De Novo cardioverter defibrillator implantation insights from the Ontario ICD database. J Am Coll Cardiol 2010; 55:774-82. doi:10.1016/j.jacc.2009.11.029

55 Bardy GH, Smith WM, Hood MA. An entirely subcutaneous implantable cardioverter-defibrillator. N Engl J Med 2010; 363:3644. doi:I0.1056/NEJMoa0909545

56 Cleland JG, Coletta AP,Yassin A et al. Clinical trials update from the American College of Cardiology 2008: CARISMA,TRENDS, metaanalysis of Cox-2 studies, HAT,ON-TARGET,HYVET, ACCOMPLISH, MOMENTUM, PROTECT, HORIZON-HF and REVERSE. Eur J Heart Fail 2008; 10:6I4-20. doi:I0.10I6/j.ejheart.2008.05.003

57 Luu M, Stevenson WG, Stevenson LW et al. Diverse mechanisms of unexpected cardiac arrest in advanced heart failure. Circulation 1989; 80:1675-80. 
58 Faggiano P, d'Aloia A, Gualeni A et al. Mechanisms and immediate outcome of in-hospital cardiac arrest in patients with advanced heart failure secondary to ischemic or idiopathic dilated cardiomyopathy. Am J Cardiol 200I; 87:655-7. doi:10.1016/S0002-9149(00)01450-8

59 Cazeau S, Leclercq C, Lavergne $T$ et al. Effects of multisite biventricular pacing in patients with heart failure and intraventricular conduction delay. N Engl J Med 200I; 344:873-80. doi:I0.1056/ NEJM200I0322344I 202

60 Leclercq C, Walker S, Linde C et al. Comparative effects of permanent biventricular and right-univentricular pacing in heart failure patients with chronic atrial fibrillation. Eur Heart J 2002 23: I 780-7. doi: I0.1053/euhj.2002.3232

6I Higgins SL, Hummel JD, Niazi IK et al. Cardiac resynchronization therapy for the treatment of heart failure in patients with intraventricular conduction delay and malignant ventricular tachyarrhythmias. J Am Coll Cardiol 2003; 42:1454-9. doi:10.1016/ S0735-1097(03)01042-8

62 Young J, Abraham WT, Smith AL et al. Combined cardiac resynchronization and implantable cardioversion defibrillation in advanced chronic heart failure: the MIRACLE ICD trial.JAMA 2003 289:2685-94. doi:I0.I00I/jama.289.20.2685

63 Abraham WT, Young JB, León AR et al. Effects of cardiac resynchronization on disease progression in patients with left ventricular systolic dysfunction, an indication for an implantable cardioverter-defibrillator, and mildly symptomatic chronic heart failure. Circulation 2004; II0:2864-8. doi:I0.II6I/0I. CIR.0000I46336.9233I.DI

64 Cleland JG, Daubert J-C, Erdmann E et al. The effect of cardiac resynchronization on morbidity and mortality in heart failure. N Engl J Med 2005; 352: I539-49. doi:I0.1056/NEJMoa050496

65 Beshai JF, Grimm RA, Nagueh SF et al. Cardiac-resynchronization therapy in heart failure with narrow QRS complexes. N Engl J Med 2007; 357:246I-7I. doi:I0.1056/NEJMoa0706695

66 Linde C,Abraham WT, Gold MR et al. Randomized trial of cardiac resynchronization in mildly symptomatic heart failure patients and in asymptomatic patients with left ventricular dysfunction and previous heart failure symptoms. J Am Coll Cardiol 2008; 52:1834 43. doi:10.1016/j.jacc.2008.08.027

67 Gras D, Lunati M, Wellens HJ et al. Implantation of cardiac resynchronization therapy systems in the CARE-HF trial: procedural success rate and safety. Europace 2007; 9:516-22 doi: I0.1093/europace/eum080

68 Cleland JG, Calvert M, Verboven $Y$ et al. Effects of cardiac resynchronization therapy on long-term quality of life: an analysis from the CArdiac REsynchronization-Heart Failure (CARE-HF) study. Am Heart J 2009; I57:457-66. doi:I0.I0 I6/j.ahj.2008.I I.006

69 Ghio S, Freemantle N, Scelsi L et al. Long-term left ventricular reverse remodelling with cardiac resynchronization therapy: results from the CARE-HF trial. Eur J Heart Failure 2009; II:480-8. doi:10.1093/eurjhf/hfp034

70 Cleland JG, Freemantle N, Daubert J-C et al. Long-term effect of cardiac resynchronisation in patients reporting mild symptoms of heart failure: a report from the CARE-HF Study. Heart 2008; 94:278-83. doi:I0.I I36/hrt.2007.12899|

7I Berger R, Shankar A, Fruhwald F et al. Relationships between cardiac resynchronization therapy and NT-BNP in patients with heart failure and markers of cardiac dyssynchrony: an analysis from the CARE-HF trial. Eur Heart J 2009; 30:2 109-16. doi:I0. I093/eurheartj/ehp2I0

72 Cleland JG, Tavazzi L, Daubert J-C et al. Cardiac resynchronization therapy. Are modern myths preventing appropriate use? J Am Coll Cardiol 2009; 53:608-II. doi:I0.1016/j.jacc.2008.10.040

73 Whinnett ZI, Davies JE, Willson K et al. Haemodynamic effects of changes in atrioventricular and interventricular delay in cardiac resynchronisation therapy show a consistent pattern: analysis of shape, magnitude and relative importance of atrioventricular and interventricular delay. Heart 2006; 92:1628-32. doi:10.1136 hrt.2005.08072I

74 Raphael CE,Whinnett ZI, Davies JE et al. Quantifying the paradoxica effect of higher systolic blood pressure on mortality in chronic heart failure. Heart 2009; 95:56-62. doi: I 0.I I36/hrt.2007.134973
75 Cleland J, Freemantle N, Ghio S et al. Predicting the long-term effects of cardiac resynchronization therapy on mortality from baseline variables and the early response: a report from the CARE-HF (CArdiac REsynchronisation in Heart Failure) trial. J Am Coll Cardiol 2008; 52:438-45. doi: I0.10I6/j.jacc.2008.04.036

76 Richardson M, Freemantle N, Calvert MJ et al. Predictors and treatment response with cardiac resynchronization therapy in patients with heart failure characterized by dyssynchrony: a predefined analysis from the CARE-HF trial. Eur Heart J 2007; 28:1827-34. doi:10.1093/eurheartj/ehm I92

77 Gervais R, Leclerq C, Shankar A et al. Surface electrocardiogram to predict outcome in candidates for cardiac resynchronization therapy: a sub-analysis of the CARE-HF trial. Eur J Heart Fail 2009; I I:699-705. doi:I0.1093/eurjhf/hfp074

78 Wikstrom G, Lundqvist CB,Andren B et al.The effects of aetiology on outcome in patients treated with cardiac resynchronization therapy in the CARE-HF trial. Eur Heart J 2009; 30:782-8. doi:10.1093/eurheartj/ehn577

79 Cleland JG, Pennell DJ, Ray SG. Myocardial viability as a determinant of the ejection fraction response to carvedilol in patients with heart failure (CHRISTMAS trial): randomised controlled trial. Lancet 2003; 362:I4-2I. doi:I0.I0I6/S0I40-6736(03) I380I-9

80 Uretsky BF, Thygesen K, Daubert JC et al. Predictors of mortality from pump failure and sudden cardiac death in patients with systolic heart failure and left ventricular dyssynchrony: results of the CARE-HF trial. J Card Fail 2008; 14:670-5. doi:10.1016/j. cardfail.2008.06.00I

8I Leclercq JF, Maisonblanche P, Cauchemez B et al. Respective role of sympathetic tone and of cardiac pauses in the genesis of 62 cases of ventricular fibrillation recorded during Holter monitoring. Eur Heart J 1988; 9: 1276-83.

82 Drew BJ, Ackerman MJ, Funk M. Prevention of torsade de pointes in hospital settings: a scientific statement from the American Heart Association and the American College of Cardiology Foundation. J Am Coll Cardiol 2010; 55:934-47. doi:I0.1016/j.jacc.2010.01.00I

83 Viskin S. Long QT syndromes and torsade de pointes. Lancet 1999 354:1625-33. doi: I0.1016/S0140-6736(99)02 107-8

84 Moss AJ, Liu JE, Gottlieb S et al. Efficacy of permanent pacing in the management of high-risk patients with long QT syndrome. Circulation 1991; 84:1524-9.

85 Abraham WT, Smith AL, the MIRACLE Study Group. A multivariate assessment of cardiac resynchronization therapy on morbidity and mortality. Eur J Heart Failure 2003; 2(Suppl I): I48 (Abstract 709).

86 Hummel JP, Lindner JR, Belcik JT et al. Extent of myocardial viability predicts response to biventricular pacing in ischemic cardiomyopathy. Heart Rhythm 2005; 2:121I-7. doi:10.1016/j. hrthm.2005.07.027

87 Feldman AM, de Lissovoy LG, Bristow MR et al. Cost effectiveness of cardiac resynchronization therapy in the Comparison of Medical Therapy, Pacing, and Defibrillation in Heart Failure (COMPANION) trial. J Am Coll Cardiol 2005; 46:23II-2I. doi:I0.1016/j.jacc.2005.08.033

88 Yao G, Freemantle N, Calvert $M$ et al. The long-term costeffectiveness of cardiac resynchronization therapy with or without an implantable cardioverter-defibrillator. Eur Heart J 2007; 28:425I. doi:I0.1093/eurheartj/ehl382

89 Clark AL, Goode K, Cleland JG. The prevalence and incidence of left bundle branch block in ambulant patients with chronic heart failure. Eur J Heart Fail 2008; 10:696-702. doi:10.1016/j. ejheart.2008.05.001

90 Aranda JM, Carlson ER, Pauly DF et al. QRS duration variability in patients with heart failure. Am J Cardiol 2002;90:335-7. doi: I0.1016/ S0002-9|49(02)02479-7

91 Bourge RC,Abraham WT,Adamson PB et al. Randomized controlled trial of an implantable continuous hemodynamic monitor in patients with advanced heart failure: the COMPASS-HF study. J Am Coll Cardiol 2008; 5I:I073-9. doi:I0.1016/j.jacc.2007.10.06I

92 Adamson PB, Smith AL, Abraham WT et al. Continuous autonomic assessment in patients with symptomatic heart failure. Circulation 2004; I I0:2389-94. doi:I0.I I6I/0I.CIR.0000I3984I.42454.78 
93 Clark RA, Inglis SC, McAlister FA et al. Telemonitoring or structured telephone support programmes for patients with chronic heart failure: systematic review and meta-analysis. BM 2007; 334:942. doi:I0.II36/bmj.39|56.536968.55
94 Cleland JG, Lewinter C, Goode KM. Telemonitoring for heart failure: the only feasible option for good universal care? Eur J Heart Fail 2009; I I:227-8. doi:I0.1093/eurjhf/hfp027

\section{SELF-ASSESSMENT QUESTIONS}

\section{Primary prevention use of implantable cardiac defibrillators (ICD) implies:}

A. Implanting a device into all patients with a family history of sudden death.

B. Implanting a device in all patients following a primary percutaneous intervention (PPCl).

C. Implanting a device as the first step in heart failure device care.

D. Implanting an ICD without a history of syncopal ventricular tachycardia.

E. The prevention of sudden death after successful primary rescuscitation.

\section{Which two of the following statements are true?}

A. The cost-effectiveness of ICD implantation after resuscitated cardiac arrest due to ventricular fibrillation is unclear.

B. The impact of primary prevention ICD implantation is of the order of one to two deaths deferred per year in cases selected on the basis of current NICE criteria.

C. There is no evidence of harm associated with recurrent ICD activation provided that this is due to correctly detected ventricular tachyarrhythmia.

D. Young patients ( $<60$ years) with left ventricular systolic dysfunction have clearly more to gain by prophylactic ICD implementation due to the cumulative benefit of longer life expectancy.

E. Repeated need for generator replacement, while expensive, is associated with minimal or no risks to treated patients.

3. Which of the following statements is correct when considering biventricular pacing indications?

A. Patients with right bundle branch block respond just as well as those with left bundle branch block.

B. Patients with atrial fibrillation show no evidence of benefit from cardiac resynchronisation therapy (CRT).

C. There is a clear relationship between a response to CRT and a wide range of echocardiographic markers of left ventricular filling and contraction.
D. Some patients may fail to achieve transvenous pacing capture despite multiple lead positioning, and can be considered for epicardial lead placement.

E. Scarring of the myocardium has no impact on lead placement or outcomes in response to CRT.

4. Combined CRT and ICD functionality (CRT-D) is associated with which of the following benefits?

A. A possible role for bradyarrhythmia pacing in preventing sudden death or escape tachycardia.

B. Synergistic benefits from resynchronisation and active defibrillation capacity.

C. Clinically obvious rises in systolic blood pressure, reduced symptoms and improvements in ejection fraction not seen with either treatment modality alone.

D. A significant reduction in the overall costs of therapy.

E. A smaller device 'footprint' that has little impact on procedure time and complication rates compared with CRT-D alone.

5. Which of the following summary statements is true for device therapy?

A. The impact on event rates due to CRT-D is 50/50 due to CRT and ICD function respectively.

B. Correcting cardiac dyssynchrony by improving ejection fraction through CRT-P may have an anti-arrhythmic effect as well as altering pump function.

C. Multiple comparative randomised trials of ICD vs CRT-D all show the latter modality to be superior in every way.

D. There is already a good evidence base that CRT is effective in left ventricular systolic dysfunction even in the absence of any heart failure symptoms.

E. Remote device monitoring reduces morbidity and mortality in all randomised controlled trials of this technology.

For the answers, please turn to page 286. 